\title{
Consumo e diferenciação social: representações ficcionais dos espaços de refeição'
}

\section{Consumption and social differentiation: fictional representations of mealtime spaces}

\author{
Marcia Perencin Tondato
}

Doutora em Comunicação pela ECA/USP, docente do PPG Comunicação e Práticas de Consumo da

ESPM

Resumo: Como se organizam os meios para que seus produtos sejam oferecidos a seus usuários como produtos de comunicação? Esta é a pergunta que sustenta e justifica o estudo da gramática dos meios, segundo a articulação de códigos eletrônicos geradores das linguagens icônicas em processos perceptuais e cognitivos. Orienta-se pelas exploraçóes que Marshall McLuhan formulou em suas análises e exercícios de seu projeto pedagógico e também na metodologia semiótica dos processos de articulação sintática, semântica e pragmática. Palavras chave: Gramática dos meios. Linguagem icônica. Percepção

Abstract: How do media organize themselves so that their products are offered to its users as forms of communication? This is the question that sustains and justifies the grammatical study of media according to the articulation of electronic codes and the iconic languages of perceptual and cognitive process. Following Marshall McLuhan analysis and pedagogic exercises the essay is oriented by the semiotic process based on syntactic, semantic, and pragmatic methodology

Keywords: Grammar of media, Iconic languages. Perception

${ }^{1}$ Uma versão inicial deste artigo, com base no mesmo levantamento de cenas, foi apresentada no NP Ficção Seriada no XXXV Congresso da Intercom, Fortaleza, setembro/2012. 


\section{Introdução}

$\mathrm{Na}$ vida real - com representação na literatura, nas artes plásticas, nos produtos midiáticos -, o ato de alimentar-se passou do cozimento e ingestão de alimentos para a realização de um ato social, de união. Refeiçóes em família, encontros em locais públicos, salas de jantar sofisticadas e simples, restaurantes populares e requintados permeiam as histórias ficcionais, reproduzindo o simbólico e alimentando o imaginário das audiências.

Desde as produçôes ficcionais importadas, entre elas alguns ícones da exportação do american way of life (Papai Sabe Tudo e I love Lucy), ${ }^{2}$ os espaços de refeição em família e, em alguns casos, também os públicos, invariavelmente compóem a cenografia, contextualizando as relaçóes e organizando a temporalidade das tramas na cotidianidade dramática. Entretanto, pouco, ou quase nada, é encontrado nas reflexôes acadêmicas sobre a representação ficcional destes espaços específicos, reflexo talvez da centralidade dos estudos em assuntos relacionados ao universo masculino (semelhante ao que ocorre em outras áreas, como a Antropologia), posto que a comida e suas preparaçóes são "vistas como trabalho de mulher [...] e o estudo da comida é considerado prosaico e pouco importante", conforme aponta Mintz (2001, p.32) em uma revisão sobre estudos de hábitos alimentares.

$\mathrm{Na}$ relação sociedade-mídia, a mídia se torna um campo de batalha ideal ao disseminar os parâmetros de uma disputa envolvendo crenças e ideologias, hábitos e percepçôes, trabalhando em favor da manutenção do status quo da elite dominante. Neste sentido, ela exerce poder ao "representar" situações, indivíduos e acontecimentos por meio de estereótipos (no âmbito do indivíduo) e mitos fundadores (no âmbito do coletivo nacional), tendo que trabalhar com o sistema linguístico e o cultural, que, por princípio, estão estreitamente ligados às relaçóes de poder (SILVA, 2009, p. 91).

Em se tratando de ficção televisiva, é importante considerar que a questão da identificação com as representaçóes passa pelo reconhecimento de si (real) no Outro (aqui, ficcional), e o que importa neste artigo: "comer é uma atividade humana central [...] representa uma base que liga o mundo das coisas ao mundo das ideias por meio dos nossos atos [...] uma base para nos relacionarmos com a realidade" (MINTZ, 2001, p. 32). Tendo em vista esse papel da alimentação para o ser humano e para a sociedade, sua representação deve ser o mais fiel possível, porém, sem os dissabores da realidade, das carências e dos excessos. "A telenovela tem que ser verossímil, embora não corriqueira. Tem que ser dramática, e, ainda assim, semelhante à vida. O drama, alguém já disse, é a vida sem as manchas de monotonia" (MOTTER, 2003, p.174).

\footnotetext{
${ }^{2}$ Papai sabe tudo, no original Father knows best (EUA, 1954-1960), apresentado no Brasil pela TV Tupi, na década de 1960, na Rede Globo, na de 1970, e na TV Cultura, nos anos 80). I love Lucy (EUA, 1951-1960). No Brasil exibida pela TV Tupi, entre 1958 e 1979; depois, pela TV Gazeta, em 1980, e pela TV Cultura, de 1994 a 2000. O sucesso de I love Lucy na TV Tupi de São Paulo inspirou o surgimento de uma versão nacional: Alô Doçura!, a primeira sitcom brasileira.
} 
Esta reflexão parte do princípio de que não existem necessidades "básicas"; toda atividade humana é "culturalmente significativa", sendo os indivíduos, aqui também como consumidores, responsáveis pela ressignificação dos objetos, atribuindo-lhes valores simbólicos. No consumo, tais indivíduos-sujeitos buscam não só a funcionalidade, mas os valores culturais da sociedade em que vivem, promovendo estilos de vida, constituindo suas identidades (TONDATO, 2010, p. 10). Identidades que, junto com as diferenças, fazem parte do sistema de representação, sendo compreendidas como um "aspecto exterior, um traço visível” (SILVA, 2009, p. 90) das diferenciaçóes de classe nos momentos de alimentação (entendida para além da ação, e como isso é representado na obra ficcional).

\section{Um pouco de história: a cultura das refeições}

Alimentar-se se torna um ato social a partir do momento em que o ser humano pode escolher. Depois da descoberta do fogo, da invenção da agricultura e da organização da criação de animais, o homem se capacita para identificar sabores e dar preferência a alguns deles. Comer, mais do que uma necessidade, torna-se um prazer. São instituídas "horas para refeiçôes", feitas na companhia da família ou de amigos, no cotidiano ou em dias festivos. "Usamos o ato de comer como veículo para relacionamentos sociais: a satisfação da mais individual das necessidades torna-se um meio de criar uma comunidade" (VISSER apud PILLA, 2004, p. 106).

Com a culinária, a alimentação se tornou artística. O homem melhorou as técnicas de agricultura e transformou a cozinha em fábrica. Surgiram os alimentos industrializados, que se multiplicaram, tornando-se mais acessíveis. No percurso histórico de sua transformação e de seu consumo, apesar de representar um inimigo para alguns, pelas fragilidades do ser humano, seus excessos e carências, o alimento não perde o papel de dar prazer, promover a sociabilidade e motivar a arte.

Junto com a mudança das nossas relaçôes com os alimentos, decorrente da necessidade biológica, também os espaços de refeiçôes sofreram alteraçôes, ao longo do tempo, conforme as tradiçôes hierárquicas e, consequentemente, de poder. Enquanto, na Idade Média, os grandes salóes eram o palco ${ }^{3}$ das refeições (PILLA, 2004, p. 108), no século XVIII, já são usadas mesas fixas em um espaço reservado, a sala de jantar. Mas, é somente no século XIX, que os cômodos da casa se definem, decorados com móveis específicos que indicavam o nível social dos proprietários conforme o grau de riqueza e desejo de ostentação.

\footnotetext{
${ }^{3}$ A palavra "palco" pode ser considerada literalmente, pois a mesa do senhor era colocada sobre um estrado, embora ele, sua família e servos comessem em mesas de cavaletes, desmontáveis, para que nos dias de festa servissem para dançar e outros divertimentos (PILLA, 2004, p. 108).
} 
Em tempos de pós, fast, ready, os espaços das refeiçōes, privados ou públicos, mantêm-se como marcas da temporalidade circular dos cotidianos, representados na telenovela pela rotina e repetição, e como cenários privilegiados das tramas e dramas familiares, de interaçáo social e exposiçáo de diferenças. Neste artigo reflito sobre práticas de consumo e marcas de distinção a partir das representaçôes ficcionais midiáticas dos espaços de preparação da alimentação e das situaçôes de refeiçóes em Fina Estampa (Globo, 2011) - escrita por Aguinaldo Silva e dirigida por Wolf Maia -, entendida como uma obra que tem na distinçáo social um foco de dramatização.

\section{Espaços, tramas e dramas de Fina Estampa}

Motter (2003) já nos alertava para a importância do estudo da telenovela como um espaço de interseção de discursos, de máo dupla, da vida cotidiana para a mídia e vice-versa, mantendo suas fronteiras preservadas, ao mesmo tempo em que constituem mais um discurso em ação. Uma rede de textos e discursos que acontece por meio e através dos personagens, que "são cidadãos tecendo, com arte, histórias que seduzem pelos recursos ficcionais, alicerçadas, edificadas e sustentadas pelo real vivido nos embates diários do nosso mundo individual e social” (MOTTER, 2003, p. 42).

Slater (2002, p. 131) chama nossa atenção para o fato de que "cultura na definição mais clássica, oriunda da antropologia, estava relacionada com costumes entre os quais os de alimentação são importantes objetos de estudo". O consumo de alimentos é articulado dentro de, ou em relação a, modos de vida significativos e específicos. Da mesma forma que "ninguém come 'comida': come um sanduíche, um sushi, um salgadinho, nenhum desses produtos sendo simplesmente 'comido', mas comido como 'almoço', 'aperitivo', 'lanche de escola'” (SLATER, 2002, p. 131), os espaços onde isso se realiza, nas situaçóes regulares do cotidiano, refletem também condiçóes e distinçôes sociais.

Ainda no âmbito da "cultura", vale lembrar que muito dos relacionamentos mútuos se materializa culturalmente, por meio dos bens materiais, estabelecendo identidades sociais e subjetividades, entre eles o comportamento relativo à comida (MINTZ, 2001). Na telenovela brasileira, os ambientes e as classes sociais podem perder sua clara demarcação, com os diferentes entrecruzando-se e misturando-se (MOTTER, 2003), mas é nos espaços de refeição, públicos e privados, que as distinçôes são realizadas, tanto no contexto das tramas quanto na representação cenográfica. Estereótipos de hábitos à mesa e comportamentos são enfatizados nas representaçóes das situaçóes de refeição, tornando-as momentos de reforço dos limites de convívio e inclusão social. condição distintiva das novas formas e ambientes culturais. 
Adentrando no material de observação, o fio condutor em Fina Estampa (Globo, 2011) é a mobilidade por meio do aumento dos recursos financeiros, em choque com as demarcaçóes sociais e culturais, alimentando as tramas e os dramas dos personagens. Para esta discussão, tomo como base os espaços de refeição da referida novela como lugares de convivência, uma escolha que se mostrou adequada, pois raro foi o capítulo em que tais locais não fossem cenários para os diálogos de interação e distinção dos personagens.

O núcleo central da trama é uma família que, do dia para a noite, teve acesso ao que há de melhor em termos de estilo de vida, na perspectiva do consumo de bens, com possibilidade de mudanças radicais de comportamento. Griselda (Lília Cabral) é uma mulher que sustenta a família como "marido de aluguel”, fazendo serviços de eletricista, encanadora, mecânica, e fica milionária ao ganhar R\$ 50 milhóes na Mega-Sena. De família muito pobre, veio de Açores para o Brasil aos cinco anos. Aos catorze, se casou e, aos quinze anos, foi mãe. Seu marido, Pereirinha (José Mayer), pescador, desaparece em alto-mar, deixando Griselda "temporariamente viúva" (ele reaparece depois, mudando o rumo da história, mas o foco aqui não é esse). Griselda, então, trabalha como faz-tudo para sustentar seus três filhos: Quinzé (Malvino Salvador), Antenor (Caio Castro) e Amália (Sophie Charlotte). Muito competente, é conhecida por todo o Jardim Oceânico, região da Barra da Tijuca (Zona Oeste do Rio de Janeiro), como Pereirão. Sem vaidades, coloca o bem-estar de sua família sempre em primeiro lugar. Ainda pobre, seu destino se cruza com René Velmont (Dalton Vigh), quando faz um reparo em seu carro, sendo então contratada para pequenos serviços em sua mansão e em seu restaurante, onde ele atua como chefe de cozinha.

René é casado com Tereza Cristina (Christiane Torloni), uma mulher fútil e mau caráter, o oposto de Griselda. Mãe de Patrícia (Adriana Birolli) e René Junior (David Lucas), Tereza Cristina acredita ter a vida perfeita. Com a fortuna que herdou dos pais, mantém um sofisticado padrão de vida, que inclui uma mansão na Barra da Tijuca e um mordomo a sua disposição, Crô (Marcelo Serrado). Apaixonada pelo marido, ela o presenteou com o restaurante Le Velmont, um dos mais requintados e bem conceituados da cidade. $\mathrm{O}$ antagonismo entre as personagens (cujos filhos são namorados), além da disputa pelo amor de René, conduz a narrativa. Patrícia é uma jovem estudante que não tem nada a ver com a personalidade esnobe e dondoca da mãe, já Antenor, o filho de Griselda, tem vergonha da mãe e dos irmãos, odiando a vida de pobre que eles têm.

O casal Álvaro Siqueira (Wolf Maia) e Zambeze (Totia Meirelles) centralizam outro núcleo dramático. $\mathrm{O}$ casal, que se conheceu em um retiro no Tibete, administra a pousada Recanto da Zambeze - segundo práticas naturais, ecológicas, de cultivo e preparo da alimentação e organização dos ambientes - e 
um quiosque à beira-mar, um "ponto de encontro" dos personagens das diversas origens econômicas, para degustar sucos de frutas naturais ou ter seçôes de massagem com Zambeze. O português Guaracy (Paulo Rocha) é dono de um bar popular, o Tupinambar, e protagoniza outro núcleo de intersecção das tramas, pois, mesmo apaixonado por Griselda, se envolve com Esther Wolkoff (Júlia Lemmertz). Esther é uma mulher muito elegante que ama muito seu marido, Paulo (Dan Stulbach), irmão de Teresa Cristina, que é estéril e não concorda com o tratamento proposto por Dra. Danielle Fraser (Renata Sorrah) para que Esther realize o sonho de ser mãe.

Outro drama é o de Celeste (Dira Paes), casada com Baltazar (Alexandre Nero). Baltazar é um homem cruel que impóe seu poder sobre a família frequentemente, usando da força física, descarregando sobre esposa e filha todas as humilhaçóes e pressóes sofridas como motorista de Tereza Cristina. Entretanto, com o incentivo e apoio de Griselda, vizinha e comadre, única e melhor amiga, Celeste finalmente denuncia o marido à Delegacia da Mulher e, a partir daí, começa sua independência, inclusive financeira, ao ter Griselda como sócia para a abertura de um restaurante de especializado em comida "brasileira", O Tempero da Celeste, que funciona em sua própria casa. ${ }^{4}$

Diferentemente ou mais enfatizado que em outras produçôes, os locais de refeição são cenário regular em todos os capítulos. As passagens entre os núcleos dramatúrgicos são marcadas/apontadas por uma tomada panorâmica do local onde se desenvolverão - seja a casa de Griselda "pobre”; a fachada de sua mansão quando "milionária”; os jardins da mansão de Teresa Cristina, as duas localizadas no condomínio (fictício) Marapendi Dreams; a fachada do Tupinambar; da Fashion Moto, onde trabalha o namorado de Amália, filha de Griselda; ou a entrada do restaurante Le Velmont. Outros cenários são os locais de estudo (a faculdade, a creche, as escolas de nível médio); a entrada do Recanto da Zambeze e a comunidade onde vivem Dagmar (Cris Vianna), cozinheira do Tupinambar, Crô e a família de Celeste; além da praia, tendo o Quiosque da Zambeze como referência.

\section{A sala de refeições e a cozinha: espaços de exposição e interação}

\footnotetext{
Há na cozinha a intimidade familiar, os investimentos afetivos, simbólicos, estéticos e econômicos. Na cozinha despontam as relaçôes de gênero, de geração, da distribuição das atividades, que traduzem uma relação de mundo, um espaço rico em relaçóes sociais, fazendo com que a mesa se constitua, efetivamente, num ritual de comensalidade. A cozinha é, portanto, um espelho da sociedade, um microcosmo da sociedade, é a linguagem da sociedade. (SANTOS, 2005)
}

\footnotetext{
${ }^{4}$ Disponível em: http://memoriaglobo.globo.com/Memoriaglobo/0,27723,GYN0-5273-278317,00.html e http:// pt.wikipedia.org/wiki/Fina_Estampa.
} 
Em Fina Estampa, várias situaçôes se desenrolam nas cozinhas: da mansão, das casas populares, do restaurante, do bar. A cozinha é o centro de reunião da família Velmont, especialmente pela manhã, enquanto o pai prepara "panquecas voadoras" para o café. Também no Recanto da Zambeze muitos diálogos se desenvolvem durante o café da manhã, com todos saboreando os quitutes preparados com ingredientes produzidos na horta do próprio Recanto ou produtos integrais e naturais. A cozinha das famílias dos núcleos populares, além de espaço de preparo, é também local de consumo das refeiçóes, como na casa de Dagmar e Celeste. Também é na cozinha do restaurante Le Velmont que René e Teresa Cristina tentam chegar a um acordo a respeito das intrigas familiares. É, enquanto prepara um café ou frita um robalo na cozinha da antiga casa de Griselda, que Pereirinha (José Mayer), marido desaparecido que retorna, discute seus planos com Enzo (Júlio Rocha) ou implica com a nora, Teodora (Carolina Dieckmann), ex-mulher de Quinzé (Foto 1). ${ }^{5}$

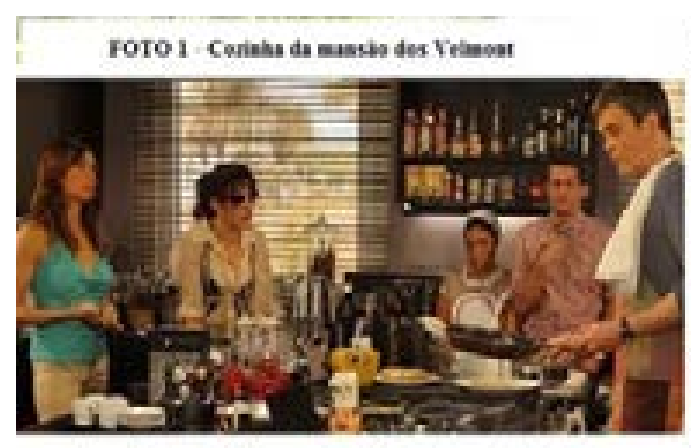

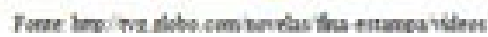

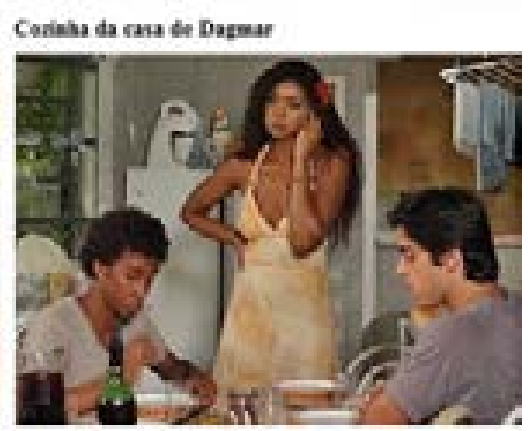

Partem também deste espaço as açôes educativas da telenovela. René Velmont discursou sobre o uso do azeite com seus assistentes de cozinha, enquanto Guaracy mostrou ao primo que esse azeite (o Gallo) era bem aceito pela clientela de seu armazém/padaria. Mesmo em se tratando de um merchandising, abordo isso do ponto de vista da ação educativa, pois deixa implícito que não se trata de um produto de acesso exclusivo aos "ricos". A ação educativa também está implícita nos diálogos entre Tia Íris (Eva Vilma) e sua fiel escudeira Alice (Thaís de Campos). Aproveitando-se de um segredo sobre as origens de Tereza Cristina, sua sobrinha, a dupla chantageia a "dondoca", além de pedir outros "favores", avançando nas iguarias que "apanham” na despensa de Teresa Cristina. Com este consumo, Tia Íris faz questão de demarcar fronteiras sociais em relação aos hóspedes do Recanto, onde vive "de favor" por ser mãe de Álvaro, apreciando salmão defumado, vinhos, queijos, patês (para ela, símbolos de refinamento e bom gosto). Uma oposição frontal à comida saudável produzida e consumida no Recanto da Zambeze.

\footnotetext{
${ }^{5}$ Todas as imagens das cenas da novela Fina Estampa são de propriedade da Rede Globo e foram copiadas do site oficial da novela, em http://finaestampa.globo.com, cabendo à emissora todos os direitos autorais. Matérias publicadas na FSP; Jornal do Comércio (POA); Mundo do MKT; Nielsen News; OESP; Revista Imprensa; jornal Metro, entre 2007 e 2012.
} 
O Recanto da Zambeze representa um espaço de encontro e representação dos cotidianos de personagens oriundos de diferentes posiçóes sociais. Pela manhã ou à noite, na volta do trabalho, todos se encontram à mesa para refeiçóes constituídas por ingredientes alternativos, cultivados e/ou preparados da forma mais natural possível: cereais, verduras, chás, sucos. O Recanto representa a opção acessível para aqueles com limitaçôes financeiras ou o lugar "alternativo" para quem, de alguma forma, não se adapta ao sistema (Foto 2).

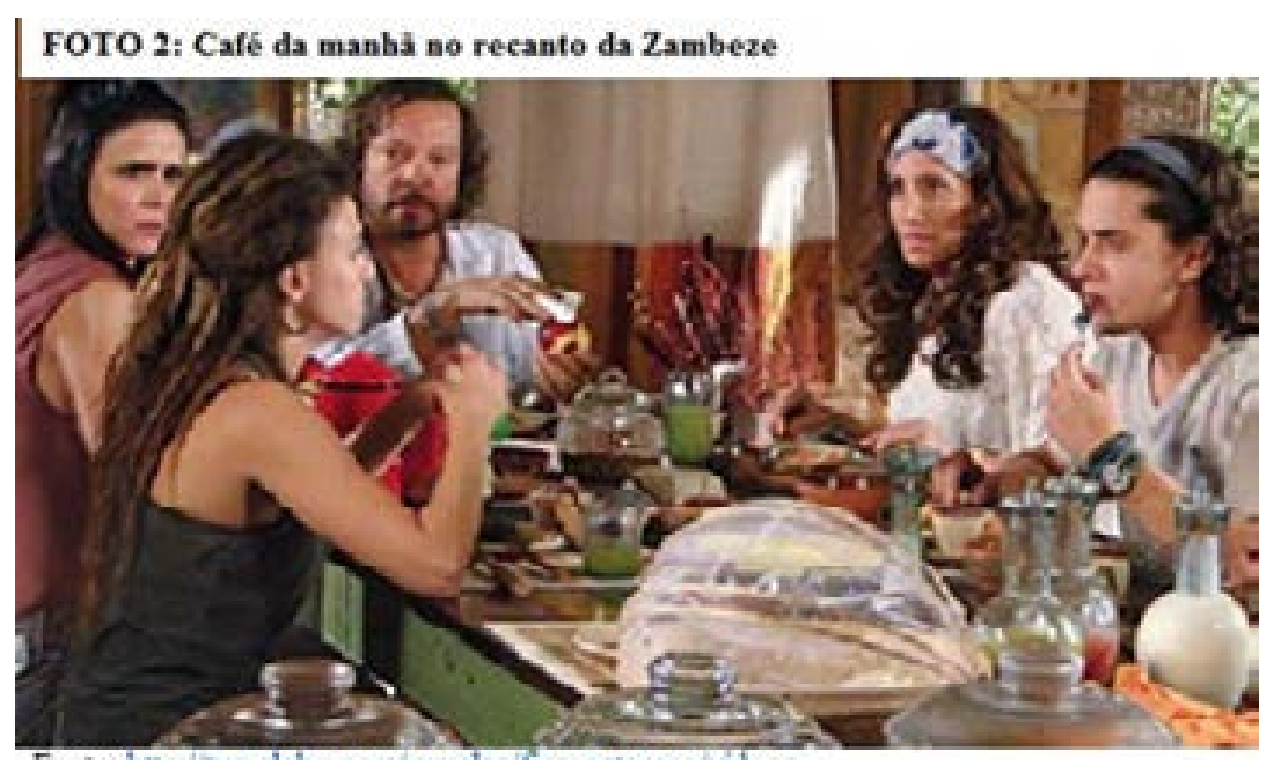

Fonte: hitto/ twe elobo com novelas fina-estamna videos

Neste sentido, recorro a Mintz (2001, p. 34), que, mesmo em uma argumentação com pouca consideração aos aspectos político-econômicos, lembra que, na China, “comer no McDonald's é sinal de mobilidade ascendente e de amor pelos filhos" e que, embora "os comportamentos relativos à comida possam ser, às vezes, simultaneamente, os mais flexíveis e os mais arraigados [...], seria mais fácil mudar o sistema político da Rússia do que fazê-los abandonar o pão preto" ou fazer que a China abandone "sua versão do socialismo mais facilmente do que o arroz".

Alguns hábitos alimentares são mais demarcados, mostrando o poder da narrativa ficcional, sua capacidade de traduzir valores, explicitar críticas a hábitos nem sempre recomendáveis, através das relaçôes afetivas, em nível do vivido, misturando-se na experiência do dia a dia, vivida ela mesma em múltiplas facetas. Logo no início da trama, Antenor exigia seu iogurte pela manhã, alegando maior necessidade por sua posição de ser "o primeiro a chegar ao ensino superior na família”. Seu sobrinho Quinzinho (Gabriel Pelícia), por sua vez, trocava a mais fina e saudável iguaria por uma pizza, preferência pela qual Teodora, sua mãe, usava e abusava no jogo de poder na relação com o pai da criança e sua família, na tentativa de demonstrar seu lado materno depois de tê-lo abandonado 
ainda bebê para ir viver com um lutador de MMA famoso. A comida é também marco de estabelecimento de poder para Baltazar, que prefere arroz, feijáo e misturas diversas - para ele, "comida do povo", "comida forte e saudável" - aos pratos finos servidos na casa de sua patroa e, principalmente, às tentativas de Celeste de variar o cardápio nas experiências de preparação para abrir seu restaurante.

Para fins da discussão aqui desenvolvida, é importante ressaltar que é principalmente a partir do século XVI que a variedade e complexidade dos utensílios usados à mesa (diversos copos e talheres) - juntamente com as maneiras distintas de servir e comer - explicitaram as diferenças sociais, aumentado "o fosso entre as elites sociais e as massas populares” (FLANDRIN apud PILLA, 2004, p. 116). Outro elemento importante na composição da mesa é a toalha, ou toalhas, conforme a época e lugar. A preferência aristocrática, que se mantém até nossos dias, é invariavelmente a toalha branca, "adamascada", adequada para os jantares formais. Impecavelmente limpa e passada. Em determinadas épocas, século XVI ao XIX, duas ou três toalhas eram colocadas sobre a mesa, sendo retiradas a cada prato servido, a sobremesa podendo ser servida sobre a mesa nua, "exibindo-se nesse caso a beleza do material de que ela era feita” (PILLA, 2004, p. 111).

$\mathrm{Na}$ casa de Teresa Cristina, as refeições, mesmo as mais formais, são servidas sobre "jogos americanos", que também aparecem na mesa de refeiçôes familiares na cozinha da Griselda "milionária”. Os "jogos americanos" surgem nos EUA na década de 1950, facilitando a vida das mulheres que, a partir de então, têm menos tempo para os afazeres domésticos ao assumirem atividades fora do lar. Em Fina Estampa, o uso na casa de Teresa Cristina denota a modernidade caracterizada pelo american way of life, ao mesmo tempo em que reproduz o uso tradicional da exibição da mesa (de pedra nobre ou cristal). Ao passo que seu uso na mansão de Griselda representa a modernidade aliada à facilidade (Foto 3).

Junto à especialização dos utensílios e ao controle das condutas, o mobiliário vai revelar um estado ou uma condição social em relação às suas significaçóes, materializando assim necessidades e direcionando-se a partir de uma linguagem silenciosa dos símbolos (PILLA, 2004, p. 108).
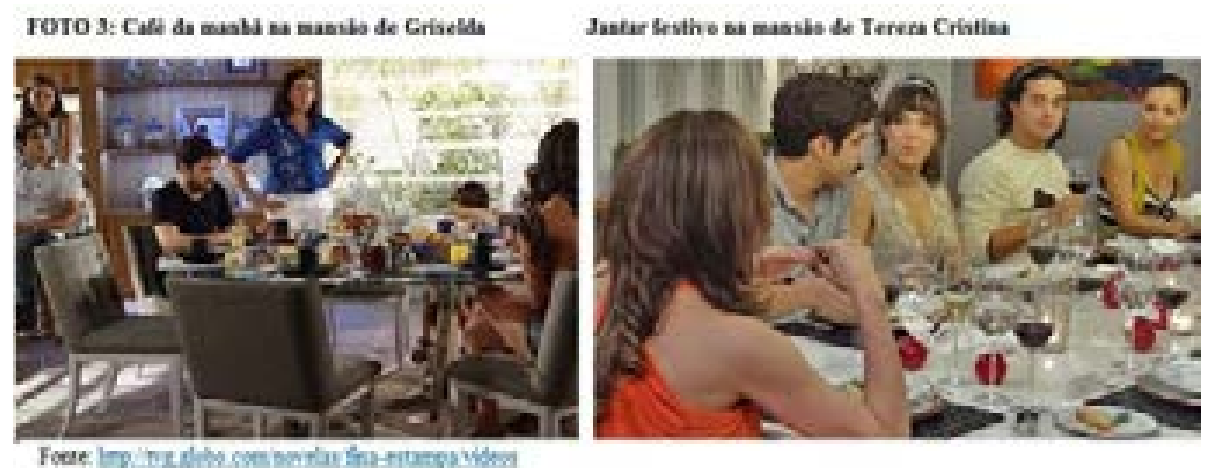

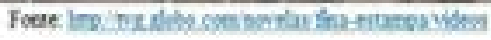


Na casa de Griselda "pobre”, a prática era o uso de toalhas de plástico grosso, resistentes e fáceis de limpar; já na mansão, a opção são os jogos americanos, mais finos, mas também práticos, tendo em vista que Griselda "milionária” optou por não ter empregados domésticos permanentes, continuando com o hábito de "cada um cuidar de si", de quando eram pobres. Também na casa da Dra. Danielle não há toalha sobre a mesa, enquanto na casa de Celeste e Dagmar a toalha de plástico forra a mesa mesmo em momentos de comemoração (Foto 4).

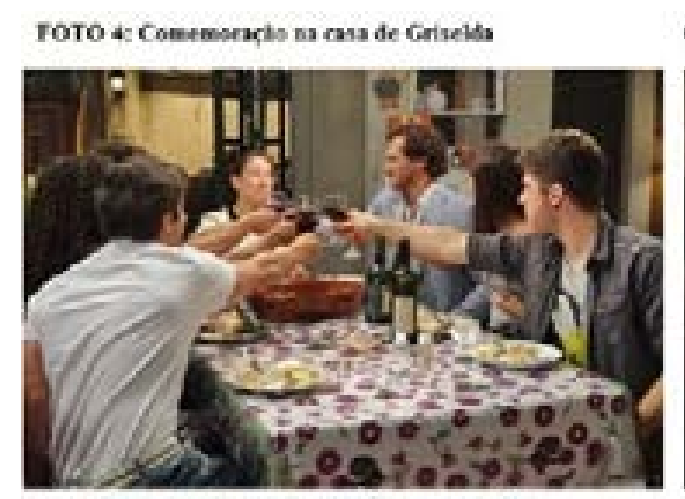

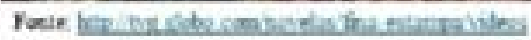

Comemoraca na casa de Celeste

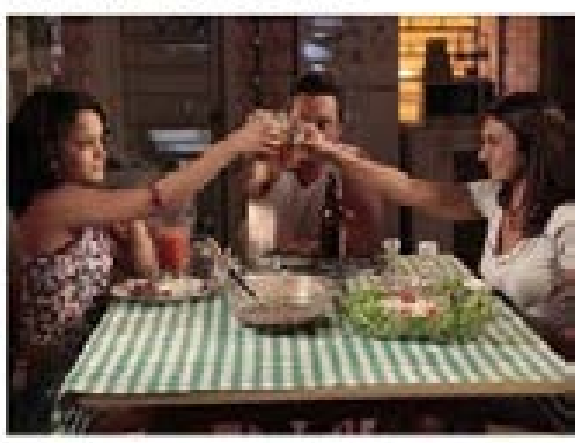

Em relação aos espaços públicos de refeição, também podemos fazer consideraçóes semelhantes a respeito da arrumação das mesas e dos utensílios utilizados. O restaurante Le Velmont contrasta com Tupinambar nas toalhas (linho x plástico) e nas mesas e cadeiras (madeira/cristal x plástico; cristais e porcelana $\mathrm{x}$ vidro e plástico). A diferenciação social nas cozinhas dos restaurantes acontece também no aspecto técnico. A cozinha do Le Velmont tem equipamentos em aço inox. No Tupinambar, o fogáo é industrial, mas de ferro. Embora as duas cozinhas se mostrem impecavelmente limpas, a disposição dos utensílios e exposição de ingredientes dos pratos a serem preparados no Tupinambar aponta menos planejamento e pouca preocupação com a estética (Fotos 5 e 6).

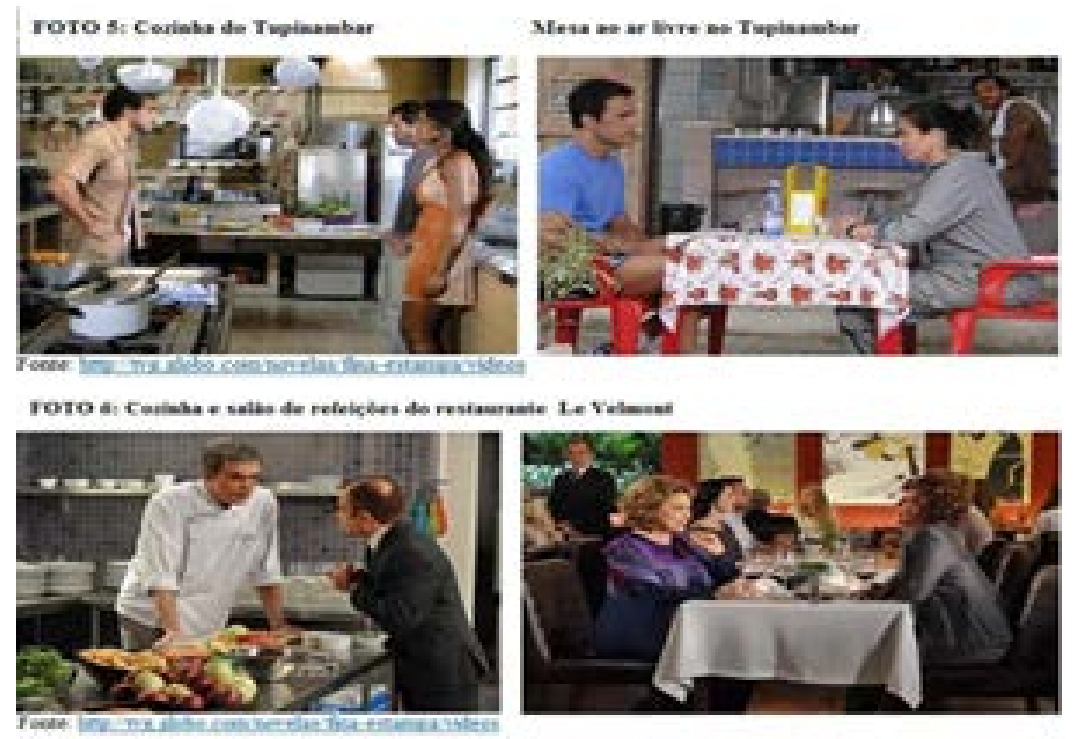


$\mathrm{Na}$ mesa da lanchonete da faculdade, de classe média alta, temos o mesmo jogo americano encontrado na mesa sofisticada e moderna. Na pizzaria e no restaurante $\mathrm{O}$ Tempero da Celeste, nota-se a intenção de uma decoração temática. A toalha branca com uma cobertura xadrez vermelho e branco, como referência à origem italiana da pizza, e o uso da madeira crua com muitas plantas e muitas cores no restaurante de Celeste, para dar um ar de aconchego e denotação da comida caseira característica do seu cardápio (Foto 7).

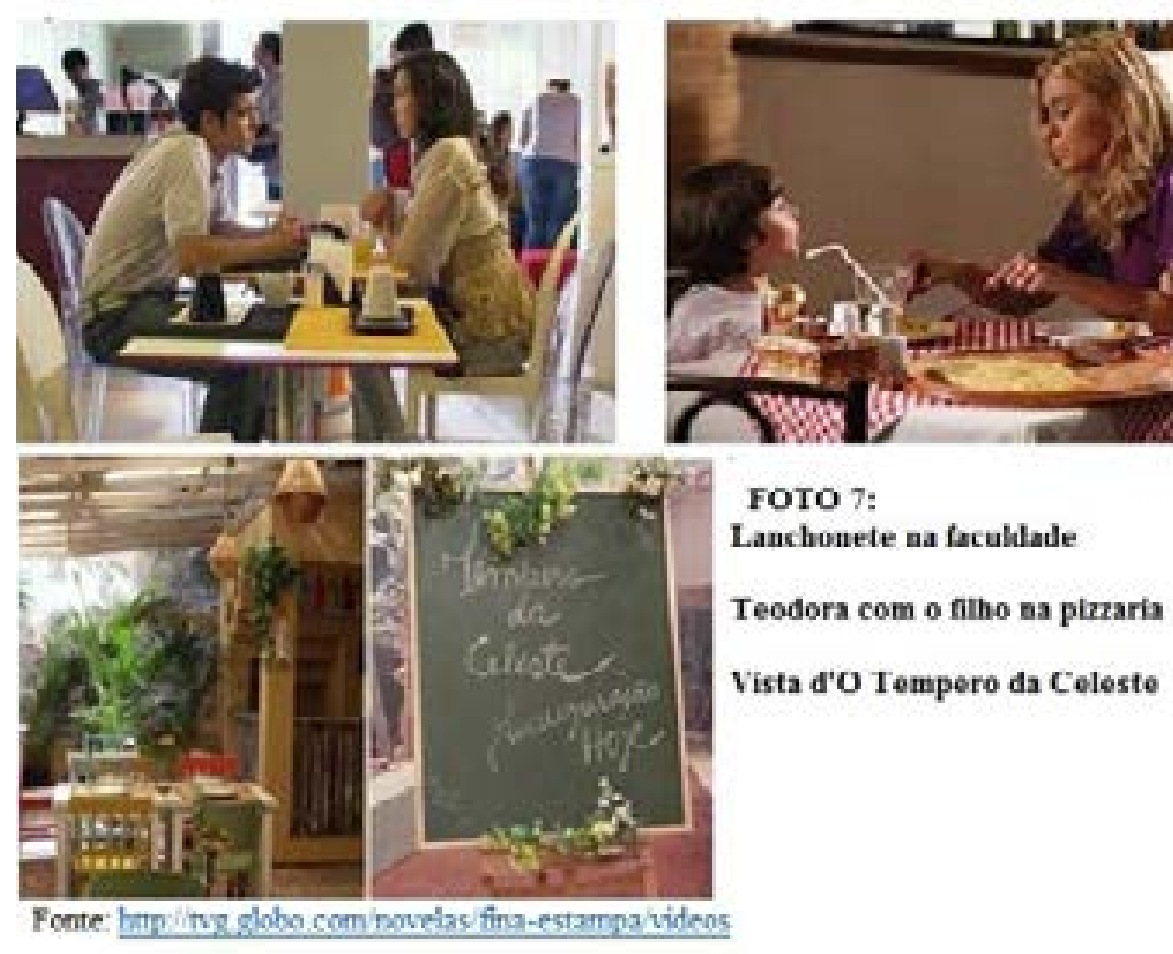

No âmbito das relações de gênero, não podemos dizer que as posiçôes tradicionais tenham sido abordadas, mesmo com a mulher sendo representada em posição de "mando" por Griselda como "marido de aluguel” e depois como proprietária de uma loja de material de construção; por Arlete Salles como motorista de táxi; ou mesmo por Amália, que começa vendendo cosméticos "naturais" manipulados, de porta em porta, e depois, torna-se dona de uma loja especializada. No núcleo de Celeste, a cozinha é o argumento de afirmação de gênero e independência. Devido a seus atributos culinários, com a ajuda da amiga milionária, Celeste monta $\mathrm{O}$ Tempero da Celeste, como já dito, marco de sua independência financeira e apoio para se livrar da violência de Baltazar. René e Celeste dirigem a cozinha de um restaurante, porém somente René desfruta da condição de grand chef, enquanto Celeste tem que se impor profissionalmente, até mesmo para seu próprio marido. Em certo sentido, uma situação que reflete a compreensão de que 


\begin{abstract}
as práticas culinárias se situam no mais elementar da vida cotidiana, no nível mais necessário e desprezado [...] atividade multiforme considerada tão simples ou até um pouco tola, salvo nos casos raros em que é elevada à excelência, ao extremo requinte - mas isso já é questão de grands chefs, que são homens, é claro. (CERTEAU, 1996, p. 218-219)
\end{abstract}

\title{
Considerações finais: indo além dos espaços de refeição
}

Mesmo que a mídia tradicional continue caracterizada como um "espelho do mundo" - deformado, mas espelho -, as verdades por ela disseminadas são cada vez menos aceitas como incontestáveis, situando-a como arena e canal para a consolidação de processos democráticos para além de ideologias partidaristas. Por outro lado, também é reforçada sua utilização como forma de poder, em virtude do estabelecimento dos megaconglomerados, limitando o acesso à produção mesmo para grupos independentes, comunitários, de vanguarda. Uma situação paradoxal que se transmuta em dialética, na medida em que, do mesmo contexto tecnológico e cultural, surgem possibilidades de expressão e manifestação para todos, caracterizando uma nova dinâmica de debate público com vistas à formação de uma opinião, se não pública no âmbito mais abrangente, compartilhada.

Tendo em conta estas relaçóes, é pertinente dizer que o coletivo passa hoje pelo consumo, pois nele os indivíduos buscam não só a funcionalidade, mas também ressignificam alguns dos valores culturais nas suas práticas, promovendo estilos de vida, constituindo suas identidades - não só como pertencimento ou como necessidade, básica ou supérflua, mas como motor de uma sociedade já denominada "do consumo". Concordando com Woodward (2009, p. 17), as representações devem fazer parte de um processo cultural, a partir do qual são estabelecidas identidades individuais e coletivas: lugares "a partir dos quais os indivíduos podem se posicionar e a partir dos quais podem falar”. Um processo que viabiliza a interpretação que os indivíduos fazem das representações, enlevando as audiências (grupos de recepção), no caso aqui das telenovelas, ao desfrute pelo reconhecimento de si, de seu estilo de vida, nos conteúdos midiáticos.

Num movimento de ousadia teórica, aproximo esta audiência (ato de recepção) pelos indivíduos-consumidores ao espectro de discussão sobre "cidadania", entendida para além do "pertencimento" também pelo "reconhecimento", que é diferente de representação. Hoje as pessoas não querem apenas "se ver representadas", elas querem ser reconhecidas na sua liberdade de escolha, em todos os âmbitos - de cultura, preferência sexual, estilo de vida, religião, fazendo-se "visíveis nas suas diferenças" (MARTIN-BARBERO, 2006).

A mídia regularmente traz o perfil do "novo" consumidor, salientando mudanças nos hábitos de um grupo que agora emerge ao consumo, listando, entre os novos desejos e aquisiçóes, a variedade de alimentaçáo (iogurtes...), o lazer diferenciado (comer fora de casa, viagens), os cuidados estéticos (manicure, pedicuro), a preocupação com educação. Neste artigo, destaquei a atividade da 
alimentação ao falar sobre a representação ficcional televisiva dos espaços destinados a esta atividade, que é "central não só por sua frequência, constante e necessária, mas também porque se torna a esfera onde se permite alguma escolha” (MINTZ, 2001, p. 32). Portanto, lugar também de diferenciação e reconhecimento. A análise das ambientaçôes das refeições no cotidiano ficcional nos aproxima das expectativas em relação ao cotidiano como lugar de construção e estabelecimento do habitus, sem que isso signifique mera reprodução e alienação - entendendo habitus como um sistema de disposiçóes decorrente de experiências passadas, duráveis (e, portanto, inscritas na construção social da pessoa) e transponíveis (que trafegam de um campo para o outro), e que estimula nos indivíduos suas percepçóes e açóes (BOURDIEU, 2008).

Nas palavras de Lull (2009, p. 96), “o espaço social se constrói na prática social e a prática não é determinada pela estrutura social". Ainda com base em Bourdieu (2008), as escolhas e preferências dos indivíduos, aparentemente voluntárias, são construídas simbolicamente como sinais da posição social, status e distinção. Assim, o estilo de vida guarda estreita relação com a posição social e reflete-se na opção pelo tipo de alimentação e padrôes estéticos (vestuário, inclusive), como evidenciam pesquisas sobre práticas culturais entre classes socioeconômicas distintas (baixo, médio e alto rendimento). Ao discorrer sobre a cultura do consumo do ponto de vista histórico, Slater (2002, p. 27, 30) ressalta que "sob o ancien régime, o status social era relativamente fixo e o consumo estava inflexivelmente ligado a uma posição social”, uma situação que se desmantela à medida que uma nova dinâmica (a da modernidade) se estabelece, reforçada pela primazia da relação "modo de vida" x "riqueza em dinheiro" e pela erosão da "sociedade tradicional".

Há muito deixamos de entender a telenovela como "mero" entretenimento. Diversos estudos trazem a telenovela como centro de reflexão sobre transformação de hábitos e até influências em culturas. As conclusóes de Motter (2003) sobre o potencial educativo, social, cultural e artístico da telenovela, ainda que entendida como entretenimento, se mostram cada vez mais substantivas. Independentemente dos aspectos de merchandising e product placement, não podemos negar as várias situaçôes educativas em Fina Estampa, que trouxeram para um público de hábitos e práticas sem sofisticação - e só agora sendo incorporado ao consumo ampliado - informaçóes sobre formas e usos de alimentos e condimentos. Num contexto de mobilidade material das classes socioeconômicas D e E, ampliando quantitativamente o grupo denominado classe $\mathrm{C},{ }^{6}$ a reprodução das práticas em curso promove a identificação tão cara à aceitação e a audiência dos programas ficcionais, enquanto a apresentação e introdução de novos hábitos e "prazeres" contribuem como açóes educativas na formação dos emergentes para a nova realidade na qual adentram.

\footnotetext{
${ }^{6}$ Estatísticas de acompanhamento da ampliação da capacidade de consumo das classes de menor renda: entre 1999 e 2009 , o percentual de brasileiros vivendo na pobreza reduziu de $11,2 \%$ para 3,8\%, e os programas de transferência de renda tiveram papel crucial neste fato. Em 2008, a denominada classe C agregava 86,2 milhóes de pessoas, o equivalente a 46\% da população brasileira (em 2005, eram 34\%), enquanto as faixas D e E
} 


\section{Referências bibliográficas}

BOURDIEU, Pierre. A Distinção: crítica social do julgamento. São Paulo: Edusp; Porto Alegre: Zouk, 2008.

CERTEAU, Michel de. A invenção do cotidiano: vol. 2. Morar, cozinhar. 2a edição. Petrópolis: Vozes, 1996.

LULL, James. Medios, comunicación y cultura: aproximación global. $2^{\text {a }}$ edição. Buenos Aires: Amorrortu, 2009.

MARTIN-BARBERO, Jesús. Tecnicidades, identidades, alteridades: mudanças e opacidades da comunicação no novo século. In MORAES, Denis de (org.). Sociedade midiatizada. Rio de Janeiro: Mauad X, 2006.

MINTZ, Sidney W. Comida e antropologia: uma breve revisão. Revista Brasileira de Ciências Sociais. Sáo Paulo: ANPOCS, vol. 16, n. 47, p. 31-41, out./2001.

MOTTER, Maria Lourdes. Ficção e realidade: a construção do cotidiano na telenovela. São Paulo: Alexa Cultural, Comunicação \& Cultura, 2003.

PILLA, Maria Cecília Barreto Amorin. A arte de receber: distinção e poder à boa mesa - 1900-1970. 2004. Tese de doutorado - Curso de Pós-Graduação em História, Departamento de História da Universidade Federal do Paraná, Curitiba, 2004. Disponível em: http://www.poshistoria.ufpr.br/documentos/2004/Mariaceciliabamorinpilla.pdf. Acesso em: 11 de junho de 2012.

SANTOS, Carlos Roberto Antunes dos. A alimentação e seu lugar na história: os tempos da memória gustativa. Revista da Academia Paranaense de Letras, n. 51, 2005, p. 165-188. Disponível em: http://www.historiadaalimentacao.ufpr. br/artigos/artigos001.htm. Acesso em: 11/junho/2012.

SILVA, Tomaz Tadeu da. A produção social da identidade e da diferença. In: SILVA, Tomaz Tadeu da (org.). Identidade e diferença: a perspectiva dos Estudos Culturais. 9a edição. Petrópolis: Vozes, 2009.

SLATER, Don. Cultura do consumo \& modernidade. São Paulo: Nobel, 2002.

TONDATO, Marcia Perencin. Uma perspectiva teórica sobre consumo e cidadania na contemporaneidade. Conexiones. Ciudad de México: Revista Iberoamericana de Comunicación, RIEC/Comunicación Social ediciones e publicaciones, vol. 2, n. 2, p. 5-18, 2010.

WOODWARD, Kathryn. Identidade e diferença: uma introdução teórica e conceitual. In: SILVA, Tomaz Tadeu da (org.). Identidade e diferença: a perspectiva dos Estudos Culturais. 9a ediçáo. Petrópolis: Vozes, 2009.

somavam 39\% (em 2005 eram 51\%). O acesso material melhora a distribuiçáo de renda, graças às políticas governamentais, ampliando em torno de $60 \%$ as classes C e B, cada uma, de 2005 a 2010 . Entretanto, para que possamos falar em um real avanço econômico-social, é preciso considerar outras frentes; há de se considerar que esta mobilidade social só se concretizará a medida que as estruturas se transformem também. 